\title{
Modern atrial and ventricular leads for permanent cardiac pacing $\star$
}

\author{
E J PERRINS, R SUTTON, B KALEBIC, L R RICHARDS, C MORLEY, \\ B TERPSTRA \\ From Westminster Hospital, London, and Medtronic BV, Holland
}

SUMmARY Three hundred and fifteen transvenous pacing leads of various modern designs have been assessed over a period of three years. Of these, 103 were implanted in the atrium and 212 in the ventricle. Screw-in leads in the right atrial appendage and short tined leads in the ventricle have resulted in the virtual elimination of lead displacement, and a very low incidence of other lead related problems. In two lead systems it has been found advantageous to have both leads constructed of urethane.

Since the first successful permanent transvenous electrode placement in 1959 by Furman, displacement of the pacing lead has remained a clinical problem. Reported displacement rates from the right ventricle have varied widely from $5 \%$ or less ${ }^{1-3}$ to above $25 \% .{ }^{4}$ Problems with transvenous atrial pacing, particularly with $\mathbf{P}$ wave sensing, in addition to lead stability, have greatly limited the application of atrial and physiological pacing systems. ${ }^{5-8}$

Lead design has improved progressively, however, and attention has focused on leads which possess a positive fixation mechanism. This may be either passive in the form of tines or flanges which engage with the myocardial trabeculae, or active involving some form of screw mechanism which penetrates the endocardium. Actively fixating leads have been used extensively in this centre since 1977 . The displacement, threshold, and follow-up data are presented for the first 103 consecutive atrial leads and 212 consecutive and concurrent ventricular leads implanted.

\section{Materials and methods}

VENTRICULAR LEADS

Two hundred and twelve leads of four differing designs have been implanted (Fig. 1). Passive tine fixation was employed with the 6951/2 and 6961/2 leads (Medtronic Inc.), both of which are constructed from silicone rubber. The 6951/2 lead had long tines $(10 \mathrm{~mm})$ set back $10 \mathrm{~mm}$ from the tip while the 6961/2 lead had much shorter tines $(2 \mathrm{~mm})$ set back $2.7 \mathrm{~mm}$

*This paper was presented in part at the November '79 meeting of the British Cardiac Society.

Received for publication 12 March 1981 from the tip. In the latter part of the study the 6971 lead was available. This is a small diameter urethane lead with $4 \mathrm{~mm}$ tines set back $2.7 \mathrm{~mm}$ from the tip.

The actively fixating type was the 6957 (Medtronic Inc.) screw-in lead. This lead, which is constructed from urethane, has a retractable helix which is

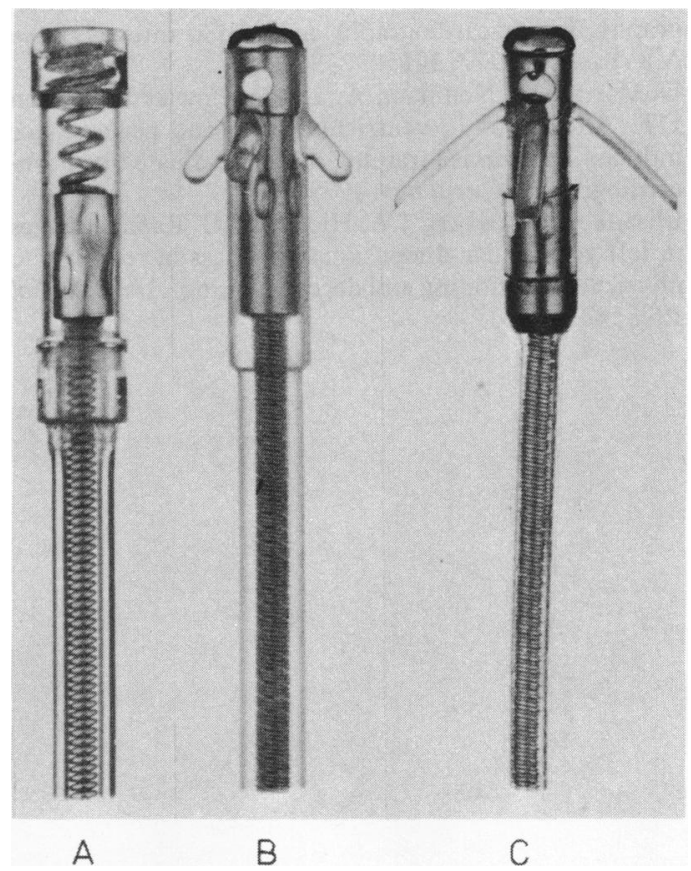

Fig. 1 Ventricular leads. (A) 6957 screw-in lead; (B) 6961 short tined lead; $(C) 6971$ urethane lead (the 6951 lead is no longer available). 
screwed out by rotating the inner core of the lead once a satisfactory $x$-ray position has been obtained. This feature allows easy passage of the lead with the helix retracted through the venous system and within the heart while still allowing the helix to be engaged with the endocardium without displacement of the tip, even if the lead is following a very tortuous path.

The leads were implanted in three series of 60 ; $6951 / 2$ alternating with $6961 / 2$ in the first, 6961/2 alternating with 6957 in the second, and 6961 alternating with 6971 in the third. The remaining leads were selected according to physician choice alone.

\section{ATRIAL LEADS}

One hundred and three leads of five differing designs were implanted (Fig. 2). Passively fixating (tined) types were the Medtronic 6991 " $\mathrm{J}$ " lead and the modified " J" or " $O$ " lead designed by one of us (BT). Both of these silicone rubber leads had three sets of long tines, but these were trimmed before insertion leaving only $2 \mathrm{~mm}$ of the set most proximal to the tip. The "O" lead had a more complete circle than the " $J$ " lead. The actively fixating types were the Osypka FY61/62 (silicone rubber) and the Medtronic 6957 (urethane). The Osypka had a non-retracting screw which required the whole body of the lead to be turned to engage it. The 6957 lead was as described above. More recently a development of the 6957 lead was used which had a "J" shaped distal portion to the lead, the Medtronic SPO295 lead. The lead was otherwise similar in construction to the 6957 lead.
LEAD PLACEMENT

Venous access was by direct cut-down on either the cephalic, subclavian, external jugular, or internal jugular vein. Two leads could often be positioned through a moderate sized cephalic vein. Ventricular leads were all positioned at the right ventricular apex using biplane screening. The atrial leads were all positioned in the right atrial appendage, except in one case when the lead was screwed into the interatrial septum. The straight atrial leads were manipulated into the atrial appendage by inserting a stylet, the end of which had been formed into a circle about $3 \mathrm{~cm}$ in diameter. When the curved stylet is inserted into the lead it causes it to take up a " $\mathrm{J}$ " shape which is then hooked up easily into the appendage. The ability to extend the helix of the 6957 lead without the rotation of the outer portion of the lead allowed easy fixation which was in contrast to the earlier Osypka lead, without this feature, which was much more difficult to screw in. Once the 6957 lead was secured in the atrial appendage considerable force was required to displace it, thereby allowing a second ventricular lead to be positioned without dislodgement of the first lead. This was particularly facilitated by the use of a urethane ventricular lead (6971) which slipped much more easily on the urethane 6957 than occurred with silicone rubber leads. The passively fixating leads ("J", " $O$ ") were much less satisfactory in this respect.

\section{MEASUREMENTS}

Electrocardiographic measurements were made endocardially on a Sandborn recorder. Both unipolar and

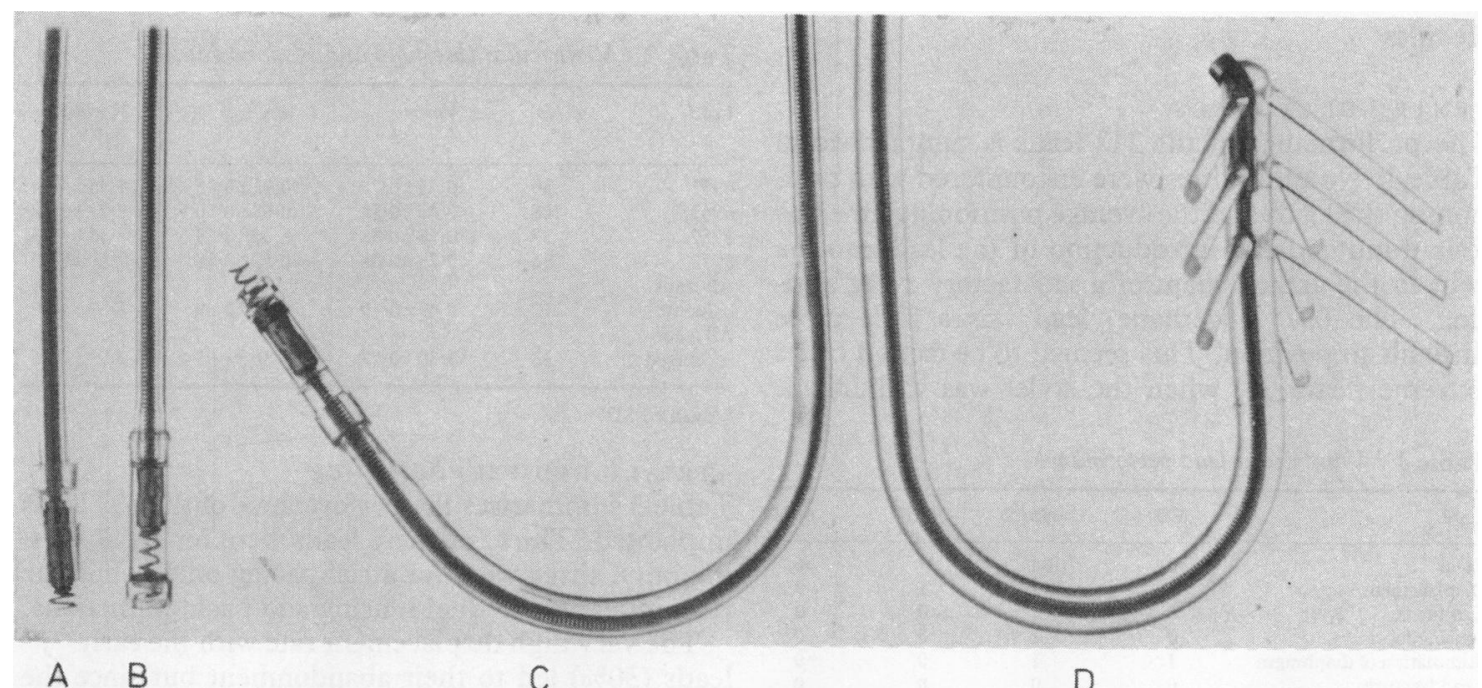

Fig. 2 Atrial leads (A) FY61 non-sheathed screw-in lead; (B) 6957 sheathed screw-in lead; (C) SPO295 f-shaped screw-in lead; (D) "Y" lead (the " $O$ " lead is no longer available). 
bipolar recordings were taken. The bipolar recording used the lead II input with the indifferent electrode situated within the pacemaker pocket. The indifferent electrode (Medtronic 6983) was of constant surface area and identical in all cases. For ventricular leads ST segment elevation and $R$ wave amplitude were measured. For atrial leads $P$ wave amplitude and $P$-Ta segment displacement were recorded. $P$ wave amplitude always varied with respiration and maximum and minimum values were recorded with deep inspiration/expiration. Threshold and $R$ wave data were obtained using a Medtronic 5300 pacemaker system analyser. Threshold was determined at pulse width durations of $1.0,0.5,0.25,0.1 \mathrm{~ms}$ in all cases. Chronic measurements were made in the same way.

FOLLOW-UP

Patients were seen at one month and then at six monthly intervals after implant. Full electrocardiographic and stability recordings were made at each visit. Chronic lead data were obtained at the time of pacemaker box change. Posteroanterior and lateral chest $x$-ray films were taken one day and one month after implant and subsequently at yearly intervals. They were compared for "subclinical displacement". Minimum follow-up time in this series was three months.

STATISTICS

All statistical analyses were by the Student's $t$ test or paired $t$ test.

\section{Results}

VENTRICULAR LEADS

The performance of the 212 leads is summarised in Table 1. No difficulties were encountered with positioning the leads and the average positioning time was four minutes from introduction of the lead into the vein to the achievement of a satisfactory $x$-ray position. The 6971 (urethane) lead was a little more difficult to position. This seemed to be caused by its extreme flexibility when the stylet was withdrawn.

Table 1 Ventricular lead performance

\begin{tabular}{lcccc}
\hline Lead & 6951 & $6961 / 2$ & 6957 & 6971 \\
\hline Total & 30 & 108 & 37 & 36 \\
Displacement & 3 & 0 & 1 & 0 \\
Exit block & 0 & $1 \star$ & 0 & 0 \\
Sensing loss & 0 & 1 & 0 & 0 \\
Stimulation of diaphragm & 1 & 1 & 0 & 0 \\
Lead fracture & 0 & 0 & 0 & 0 \\
Lead extrusion & 0 & 0 & 0 & 0 \\
Perforation & 0 & 0 & 0 & 0 \\
\hline
\end{tabular}

^Temporary.
The average positioning time for this lead was seven minutes.

The displacement rate of $10 \%$ with the long tined 6951 lead was considered to be unacceptable and its use was discontinued. In contrast there have been no displacements with the short tined 6961 lead out of 108 leads implanted. Similarly there have been no displacements with the 6971 urethane lead out of 36 implanted. There was only one displacement of a 6957 screw-in lead in the ventricle out of 37 implanted. Late complications were very few, with one case only of exit block (6951 lead), one case of late sensing failure (6961 lead), and two cases of diaphragmatic stimulation (one 6961, one 6957). Lead replacement was not required in the two patients with diaphragmatic stimulation because of the use of output programmable pacemakers. The total reoperation rate for all causes with the ventricular leads was $1.9 \%$. When the obsolete 6951 leads are excluded from the analysis this figure falls to $0.55 \%$.

Acute and chronic threshold and $\mathrm{R}$ wave data are presented in Table 2 . The lower surface area 6961 leads showed expected lower acute thresholds and $\mathbf{R}$ wave amplitudes when compared with the 6951 leads $(p<0.05)$, while the higher surface area 6957 screw-in leads showed higher thresholds acutely than the 6961 $(\mathrm{p}<0.001)$, though there was no difference in $\mathrm{R}$ wave amplitude. There was no statistically significant difference between the threshold and $R$ wave amplitude data for the 6961 and 6971 leads. All leads showed the expected highly significant chronic threshold rise $(\mathrm{p}<0.001)$ without any significant fall in $R$ wave amplitude.

Table 2 Ventricular threshold and $R$ wave data

\begin{tabular}{lrlll}
\hline Lead & No. & Volts & $m A$ & $\begin{array}{l}R \text { wave } \\
(m V)\end{array}$ \\
\hline 6951 & 30 & $0.51 \pm 0.2^{\star}$ & $0.91 \pm 0.45$ & $9.45 \pm 4.64$ \\
$6961 / 2$ & 108 & $0.40 \pm 0.18$ & $0.68 \pm 0.30$ & $7.77 \pm 3.52$ \\
6957 & 37 & $0.56 \pm 0.31$ & $1.00 \pm 0.73$ & $8.38 \pm 4.53$ \\
6971 & 36 & $0.29 \pm 0.08$ & $0.57 \pm 0.18$ & $7.60 \pm 2.90$ \\
$\begin{array}{c}\text { All leads } \\
\quad \text { (acute) }\end{array}$ & 212 & $0.47 \pm 0.19$ & $0.86 \pm 0.49$ & $8.39 \pm 4.10$ \\
$\begin{array}{c}\text { All leads } \\
\text { (chronic) }\end{array}$ & 13 & $1.30 \pm 0.77$ & $2.36 \pm 1.05$ & $2.93 \pm 2.86$ \\
\hline
\end{tabular}

${ }^{\star}$ Mean \pm 1 SD.

ATRIAL LEAD PERFORMANCE

Table 3 summarises the performance of the 103 leads implanted. Thirty of these leads were for atrial sensing only, three were for atrial pacing only, while the remainder served dual sensing and pacing functions.

The very high displacement rate with the early "J" leads (30\%) led to their abandonment but since the adoption of the " $O$ " leads and the screw-in atrial leads there has only been one further displacement out of 81 leads implanted (a 6957 lead). As already mentioned, 
Table 3 Atrial lead performance

\begin{tabular}{lccc}
\hline Lead & “g”lead & “ $O$ "lead & Screw-in leads \\
\hline Total & 22 & 15 & 66 \\
Displacement & 6 & 0 & 1 \\
Exit block & 1 & 0 & 0 \\
Sensing loss & 1 & 1 & 2,1 \\
Phrenic stimulation & 1 & 0 & 1 \\
Lead fracture & 0 & 0 & 0 \\
Extrusion & 0 & 0 & 0 \\
Perforation & 0 & 0 & 0 \\
\hline
\end{tabular}

*Temporary.

the Osypka lead was a little more difficult to use than the 6957 lead but overall there were no particular difficulties encountered with positioning the leads, the average position time being eight minutes.

Table 4 Atrial threshold and $P$ wave data

\begin{tabular}{|c|c|c|c|c|}
\hline Lead & No. & Volts & $m A$ & $\begin{array}{l}P \text { wave } \\
(\boldsymbol{m V})\end{array}$ \\
\hline $\begin{array}{l}\text { "J" } \\
\text { "O" } \\
\text { Screw-in } \\
\text { All leads } \\
\text { (acute) } \\
\text { All leads } \\
\text { (chronic) }\end{array}$ & $\begin{array}{l}22 \\
15 \\
66 \\
\\
99\end{array}$ & $\begin{array}{l}1.06 \pm 0.44^{\star} \\
0.71 \pm 0.20 \\
0.59 \pm 0.31 \\
0.78 \pm 0.31\end{array}$ & $\begin{array}{l}2 \cdot 57 \pm 1 \cdot 24 \\
1 \cdot 50 \pm 0.46 \\
0.98 \pm 0.61 \\
\\
1.68 \pm 0.57\end{array}$ & $\begin{array}{l}3.90 \pm 1.41 \\
2.95 \pm 1.59 \\
3.03 \pm 1.38 \\
3.29 \pm 1.26\end{array}$ \\
\hline
\end{tabular}

${ }^{\star}$ Mean \pm 1 SD.

The atrial threshold and $\mathrm{P}$ wave amplitude data are shown in Table 4. The passively fixating " $J$ " lead had a sigificantly higher threshold and $P$ wave amplitude than either the " $O$ " lead or the screw-in leads $(p<0.001)$. There was no significant late rise in the threshold for the " $\mathrm{J}$ " lead. There was, however, a significant late rise in threshold for the " $O$ " lead and

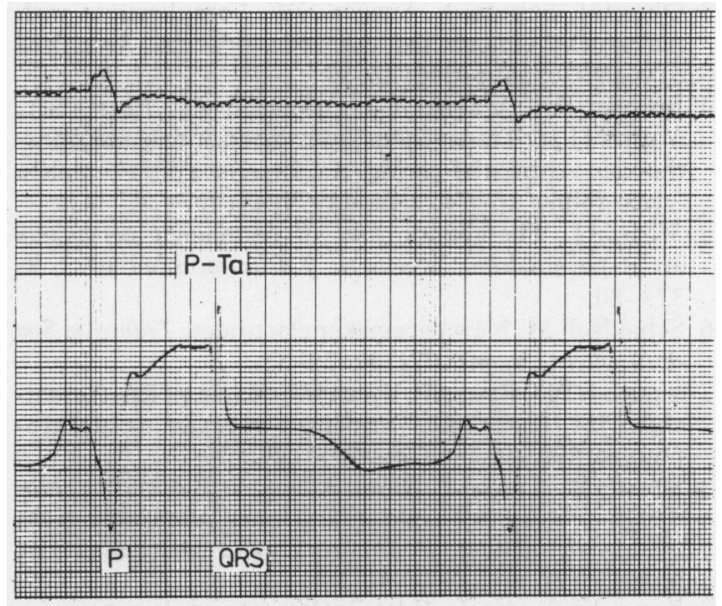

Fig. 3 Acute P Ta displacement. The upper tracing is a bipolar recording from a 6957 lead in the right atrial appendage. The lower trace is surface lead II. P T a displacement of $2.9 \mathrm{mV}$ is seen. Paper speed $100 \mathrm{~mm} / \mathrm{s}$, calibration $1 \mathrm{mV} / \mathrm{cm}$. the screw-in types. This is taken to imply better initial contact between the atrial muscle and the lead. This is further supported by the fact that, acutely, P-Ta displacement could be recorded with these leads (Fig. 3). The slight fall in $\mathbf{P}$ wave amplitude seen with all the leads was not, however, statistically significant.

When chronic atrial and ventricular lead thresholds were compared, there were no statistically significant differences between them. This was so whether both groups were compared as a whole or the identical 6957 atrial and ventricular leads were compared alone.

\section{Discussion}

Our initial experience with actively fixating leads in both chambers has been extremely encouraging. There have been no cases of lead fracture, extrusion, or perforation in either atrium or ventricle. The leads were all positioned easily and no special problems were encountered with multiple lead systems, particularly if the atrial lead was of the screw-in type and both leads were constructed from urethane.

The overall displacement rate in the ventricle was $1.89 \%$ and in the atrium $6.7 \%$. Nearly all of the displacements occurred, however, in just two kinds of lead which were implanted early on in the study. These leads were the atrial " $J$ " lead (total 22) and the 6951 long tined ventricular lead (total 30). When these leads are excluded from the analysis the displacement rates become $1.3 \%$ for the atrium (total 81 leads) and $0.55 \%$ for the ventricle (total 181 leads).

The high displacement rate of $30 \%$ seen with the " $J$ " lead was disappointing but may be in partrelated to operator technique as these were the first atrial leads we implanted. Several autho:s have reported better results, ${ }^{9-11}$ with displacement rates from 5 to $10 \%$. Geddes et al., however, using a bipolar "J" lead reported a $19 \%$ displacement rate. ${ }^{12}$

There has been no case of exit block in the atrium but there were two cases of late sensing failure (one " $O$ " lead, one 6957). At reoperation satisfactory sensing was achieved by implanting a unit with a higher atrial sensitivity.

There are relatively few data published with respect to screw-in leads implanted in the atrium, but Bisping et al. ${ }^{13}$ have implanted 23 leads of the 6957 type with no displacements and a $2 \%$ incidence of sensing problems, while Santini et al.${ }^{14}$ have reported one displacement out of 30 leads implanted (6957 and Osypka FY61). Both authors have also confirmed the much lower acute atrial thresholds seen with these leads compared with passive leads such as the "J". They have also recorded satisfactory $P$ wave amplitude $(2.5 \mathrm{mV})$ in all cases without the necessity to "search" the appendage. It is clear from our own results and from those of others that the screw-in lead 
is superior to passively fixating leads in the atrial appendage, with a displacement rate of $1.5 \%$ and a reoperation rate of $4.5 \%$.

The overall incidence of exit block in the ventricle was $0.47 \%$ but this was only temporary. There was one case of late sensing failure with a 6961 lead and two cases of diaphragmatic stimulation. The 6961 lead has shown consistently excellent results in the ventricle. Mond and Sloman ${ }^{15}$ have reported similar results with 100 leads of the 6961 type. They report no displacement, one perforation, one sensing failure, and two cases of diaphragmatic stimulation. Perforation has not occurred in this series. Beyer ${ }^{16}$ in a review of 573 ventricular leads found fixating leads to be far superior to non-fixating types and reported no displacements from 31 leads of the 6961 type implanted. Brewster and Evans ${ }^{17}$ in a 10 year actuarial study of lead longevity showed that tined leads were superior in all respects to non-tined leads. With the long tined 6950 Medtronic lead they reported a displacement rate of $7 \%$. This is similar to the $10 \%$ rate seen with the 6951 lead in this study. It is clear, therefore, that the short tined 6961 lead gives the most satisfactory results, with a displacement rate of $0 \%$ (total 108 leads) and a total complication rate of $2 \cdot 7 \%$.

We have so far seen no displacements with the 6971 urethane lead (total 36 ) but there are no published data with which to compare this. The 6957 screw-in lead has also been satisfactory though there was one displacement. Bisping et al. ${ }^{13}$ only reported one displacement out of a series of 127 of these leads in the ventricle.

A considerable number of chronic lead measurements were made during this study largely as a result of the use of early "advanced" pacemakers. These units initially tended to have mercury cells and a short life necessitating early unit replacement. $\dot{A}$ few of these units also had electrical faults leading to replacement.

The analysis of the chronic atrial thresholds has shown that chronic atrial and ventricular thresholds do not differ significantly. This means that the practice of some manufacturers in supplying atrial pacemakers with high outputs is unnecessary. In two lead systems the ability to programme both ventricular and atrial outputs to low values will have obvious energy saving advantages. The high acute thresholds seen with the " $\mathrm{J}$ " lead and confirmed by other workers $^{9-11}$ are probably the result of initial poor contact of the lead with the atrial muscle. The P-Ta segment displacement seen with the screw-in leads represents a true atrial current of injury. The P-Ta displacement is not seen chronically.

$P$ wave amplitude measured acutely has not been shown to fall significantly later. The importance of determining the maximum and minimum values during deep inspiration/expiration is emphasised. The two cases of late sensing failure, however, showed satisfactory acute measurements so that a residual small incidence of late sensing failure is at present to be expected. This problem may be largely overcome by implanting units with programmable atrial sensitivity and this facility should be provided in all two chamber pacing systems. Analysis of the chronic ventricular data showed similarly that the sensed $R$ wave did not fall significantly with time.

We conclude that satisfactory endocardial atrial pacing can be achieved using screw-in leads in the right atrial appendage with a very low rate of both displacement and other lead related problems. Modern tined ventricular leads allow an extremely low displacement rate, and rates of $1 \%$ or less are easily obtainable.

It is recommended that the lead of choice for atrial pacing is the Medtronic 6957 screw-in lead. For ventricular pacing a short tined lead with the tines set close to the tip, such as the Medtronic 6961, should be used. A screw-in lead in the ventricle would be a satisfactory alternative. In two lead pacemakers both leads should be constructed from urethane to allow maximum ease of insertion and manipulation.

\section{References}

1 Parsonnet V, Billitch M, Furman S, et al. Early malfunction of transvenous pacemaker electrodes. A threecenter study. Circulation 1979; 60: 590-6.

2 Stertzer SH, DePasquale NP, Bruno MS, Cohn LJ. Right ventricular apexangiography for precise placement of transvenous electrode catheters. Chest 1976; 69: 222-3.

3 Ohm OJ, Segadal L, Skagen DW. Complications with permanent endocardial electrode systems. Acta Med Scand 1976; suppl 596: 22-9.

4 Brenner AS, Wagner GS, Anderson ST, Rosati RA, Morris JJ Jr. Transvenous, transmediastinal, and transthoracic ventricular pacing. A comparison after complete 2 year follow up. Circulation 1974; 49: 407-14.

5 Moss AJ. Therapeutic uses of permanent pervenous atrial pacemakers: a review. $\mathcal{F}$ Electrocardiol 1975; 8: 373-80.

6 Schaldach M. New pacemaker electrodes. Trans Am Soc Artif Intern Organs 1971; 17: 29-35.

7 Smyth NPD, Basu AP, Bacos JM, Massumi RA, Kershishian JM, Baker NR. Permanent transvenous synchronous cardiac pacing. Chest 1971; 59: 493-7.

8 Sutton R, Citron P. Electrophysiological and haemodynamic basis for application of new pacemaker technology in sick sinus syndrome and atrioventricular block. Br Heart f 1979; 41: 600-12.

9 Kruse IB, Ryden L, Ydse B. Clinical and electrophysiological characteristics of a transvenous atrial lead. $\mathrm{Br}$ Heart f 1979; 42: 595-602.

10 Kleinert $M$, Bock $M$, Wilhelmi $F$. Clinical use of a new transvenous atrial lead. Am $\mathcal{F}$ Cardiol 1977; 40: 237-42. 
11 Citron P, Smyth NPD, Kleinert M, Kahn AR. Clinical experience with a new transvenous atrial lead. Chest 1978; 73: 193-7.

12 Geddes JS, Webb SW, Clements IP. Clinical experience with transvenous atrial pacing. Br Heart $\mathcal{F} 1978$; 40: 589-95.

13 Bisping HJ, Kreuzer J, Birkenheier H. Three year clinical experience with a new endocardial screw-in lead with introduction protection for use in atrium and ventricle. Pace 1980; 3: 424-35.

14 Santini M, Alliegro A, Boschetti C, Marini V. New screw in lead for transvenous atrial sensing and pacing. In: Meere C, ed. Proceedings of the VIth World Symposium on Cardiac Pacing 1979. chapter 29-7. Montreal: Pacesymp, 1979.
15 Mond H, Sloman G. The small tined pacemaker leadabsence of dislodgement. Pace 1980; 3: 171-7.

16 Beyer J. Early results with new endocardial pacing leads. In: Meere C, ed. Proceedings of the VIth World Symposium on Cardiac Pacing 1979. chapter 20-5. Montreal: Pacesymp, 1979.

17 Brewster GM, Evans AL. Displacement of pacemaker leads, a 10 year survey. Br Heart 7 1979; 42: 266-70.

Requests for reprints to Dr E J Perrins, Department of Cardiology, Westminster Hospital, Horseferry Road, London SW1P 2AP. 